\title{
Understanding the Roles of Knowledge Sharing and Trust in Online Learning Communities
}

\author{
Brian Thoms, Nathan Garrett, Jesus Canelon Herrera, Terry Ryan \\ Social Learning Software Lab, Claremont Graduate University \\ Claremont, California, USA \\ \{Brian.Thoms, Nathan.Garrett, Jesus.CanelonHerrera,Terry.Ryan\}@cgu.edu
}

\begin{abstract}
This paper builds on action and design research aimed at enhancing scholarly community and conversation in a graduate school setting. In this paper we focus on knowledge sharing (KS) and trust as important factors for building a sustainable online learning community (OLC). Guided by theories of social learning and social networking, we survey graduate students to assess their perceptions of KS and trust in communities of practice (CoPs). These results are compared against posttest results measuring community building and knowledge sharing in a stakeholder-defined OLC. Results indicate that although students' initial assessment of KS and trust in CoPs were low, users perceived high levels of value from a stakeholder-defined OLC. Our research offers a proof-of-concept that stakeholder-defined OLCs provide students with the opportunity to develop knowledge networks, while also providing for individual autonomy over their content. Our results also indicate an intriguing alternative to traditional course management systems (CMS).
\end{abstract}

\section{Introduction}

In 2005, the president of our university, a graduate school in the U.S., approached our research group with the vision of a more connected campus where individuals become active participants in the scholarly conversation. This vision goes beyond simple face-toface $(\mathrm{F} 2 \mathrm{~F})$ interactions and extends into the virtual realm to create new opportunities for learning, knowledge sharing (KS) and knowledge discovery.

As researchers in social software, our role has been to discover innovative ways where technology is able to support this vision. To this extent, we believe we have provided a portion of our school with a persistent virtual addition to the scholarly conversation.

In this research paper, we expand on a theoretical model for building communities of practice ( $\mathrm{CoPs}$ ) and use this model to implement a stakeholder-defined online learning community (OLC). Building atop ongoing action research (AR) and design research (DR), we assess individuals' motivations for sharing knowledge and trusting information within a CoP. We measure these results against the perceived value individuals receive from of a stakeholder-defined OLC.

To date, our results indicate that although individuals perceived low-levels of KS and equally low levels of trust in CoPs initially, individuals perceived high levels of value after using our OLC. These results offer a proof-of-concept that a stakeholder-defined OLC can provide for individual autonomy within a $\mathrm{CoP}$ while also fostering community building and $\mathrm{KS}$. Additionally, our research provides further support for stakeholder-defined OLCs as a valid alternative to more traditional course management systems (CMSs).

\section{Background}

\subsection{Building social capital in CoPs}

Lave and Wenger [1] define a $\mathrm{CoP}$ as a group that works together towards common goals, collaborating on common problems, sharing best practices, supporting one another and sharing a common identity. Critical for the specific knowledge needs of a $\mathrm{CoP}$ is that knowledge is self-generating and perpetuating, and that the transfer of such knowledge becomes an intrinsic function of the CoP [2]. Ultimately, sustained engagement and collaboration among individuals in a CoP will lead to boundaries that are based on shared histories of learning [3].

CoPs are often measured in terms of social capital. In a virtual setting, social capital is a common social resource that facilitates information exchange, knowledge sharing, and knowledge construction through continuous interaction, built on trust and maintained through shared understanding [4]. Social capital is built on shared social resources including a common identity, familiarity, trust, and a degree of shared language and context among individuals $[5,6]$. Huysman and Wulf [7] propose that with higher levels 
of social capital within a group, more members are stimulated to connect and share knowledge.

\subsection{KS and Trust in CoPs}

CoPs are increasingly being used in the diffusion of knowledge by streamlining workflow and sustaining intellectual capital within and across organizational boundaries [8]. KS research emphasizes that a shared understanding and a common ground among people in a community are essential for collaboration and productive knowledge transfer [1].

In effective knowledge communities, the collective knowledge of the community must be greater than the sum of any one member. As a result, reciprocation of knowledge should exist so individuals are able to gain access to the knowledge within the community and vice versa [9]. In essence, individual knowledge and collective knowledge should support one another [10].

In all types of KS activities, knowledge contributors and seekers require a common community to share general conversation, experimentation, and experiences with other people who have similar objectives [11]. In an online community, KS involves individuals using the $\mathrm{CoP}$ as a mechanism to effectively convey what they know $[12,13]$.

A key ingredient for successful KS is trust. This trust amounts to the extent to which the community is a valid source of knowledge and that the community is also a safe and reliable place for interaction [14, 15]. Furthermore, trust within a $\mathrm{CoP}$ involves the extent to which individuals rely on the community for knowledge. Wathne et al. [16] discovered a correlation between high levels of perceived trust and high levels of openness between cooperative partnerships that help to facilitate knowledge transfer. In a case study of 51 work groups, Edmundson [17] discovered that a lack of trust resulted in more individual work with little collaboration, higher rates of worker dissatisfaction, and team attrition where the opposite was true in teams with greater amounts of trust.

\section{Theory triangulation for CoPs}

To help build a sustainable online community of learners we rely on three theories of how individuals receive and process knowledge in CoPs and online learning environments (OLEs).

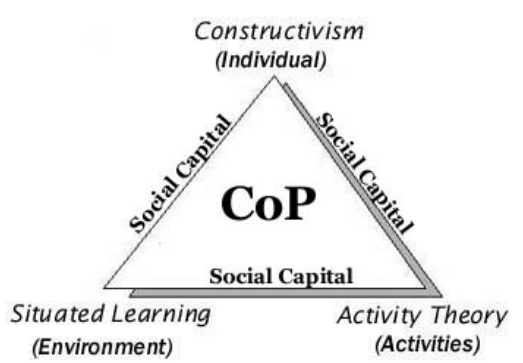

Figure 1. Theoretical model

Using Figure 1 as an illustrative model of our online CoP, we first consider the individual as a unique entity (Social Constructivism). Next we must take into account the social context in which learning occurs (Situated Learning). Finally, we consider the various activities that help facilitate both individual and group knowledge building (Activity Theory).

\subsection{Social Constructivism}

Prior research has traced the roots of a $\mathrm{CoP}$ to social constructivism [10, 18, 19]. Social Constructivism views the learner as unique and multidimensional, each with diverse needs and backgrounds. Social Constructivism encourages, utilizes, and rewards these characteristics throughout the learning process [20]. Both interaction and learning becomes a personal idiosyncratic experience, characterized by individuals developing their knowledge and understanding by forming and refining concepts. The focus of Social Constructivism is that learning is at the controls of the individual, with learners making decisions that match their own cognitive state and their own needs [21].

Although Social Constructivism began as a theory of learning, it has progressively expanded its dominion, becoming a theory of teaching, a theory of education, a theory of the origin of ideas, and a theory of both personal knowledge and scientific knowledge [22]. For our purposes, Social Constructivism plays a critical role in placing the individual at the forefront of our OLC. Individuals should be able to use the OLC, as they wish, to maximize their learning experiences. As a user-centric and user-driven tool, a stakeholderdefined OLC offers individuals total control over their own space and encourages users to explore and take ownership of the OLC.

\subsection{Social Presence Theory}

Individuals are also influenced to a great extent by their surrounding environment. Thus, when implementing an online $\mathrm{CoP}$, it is critical to consider 
the makeup of the CoP, including understanding that the community itself becomes a unique entity. Social Presence Theory looks at the degree to which individuals' perception of an online community affects his or her participation in that community. A CoP cannot exist without a palpable presence. If individuals do not perceive others within a $\mathrm{CoP}$ as real, they cannot trust that $\mathrm{CoP}$ as a valid source of knowledge building and/or social interaction.

There are several factors to consider when measuring social presence including social context, specific computer mediated communications (CMCs), and interactivity [23]. These components range from individual attitudes towards online communication to more personal attitudes towards KS and trust within CoPs. Research has shown that social presence is one of the most significant factors in improving instructional effectiveness and building a sense of community. Research by Stacey [24] discovered that establishing social presence is an important aspect for effective online interaction and learning and found that a high quality of electronic communication helps to engage students and aids in their learning of the course material.

For our specific study, an OLC will be used to compliment F2F classroom experiences therefore some degree of social presence, prior to individuals using the tool, should already exist. Our goal will be to extend the classroom experience into the virtual realm.

\subsection{Activity Theory}

Completing our theoretical model are the activities both individuals and communities utilize within an online CoP. In our specific OLC, it is those activities that individuals will utilize to share knowledge and build social capital. We use Activity Theory as a lens for understanding the sociotechnical interactive networks as a function of technology, community and individual interaction between the two. In Activity Theory, activities are goal-directed, where there exists multiple ways to achieve those goals, oftentimes through adaptive means [25].

As individuals begin to use the Web 2.0 technologies that comprise our OLC, they will also adapt their activities in order to meet their required objectives. In a study on higher education, Issroff and Scanlon [26] found that Activity Theory forces instructors to consider multiple factors that can impact a specific technologies usage. Furthermore, when able to choose educational activities from both online and F2F mediums, instructors can potentially select the activity that provides the best fit with any particular learning objective [27].

\section{Action and Design Research}

\subsection{Research Design}

This research builds on ongoing action (AR) and design research (DR) at our school looking to enhance the graduate experience and foster scholarship and conversation by implementing a stakeholder-defined OLC. More specifically, this research falls into Phase II of our AR/DR cycle, focusing on a new wave of graduate students and their perceptions after using a stakeholder-defined OLC.

During Phase I we identified a stakeholder-defined OLC as one possible artifact for complimenting faceto-face conversation at our school. The idea was inspired by popular online social networking (OSN) applications including MySpace ${ }^{\mathrm{TM}}$, LinkedIn ${ }^{\mathrm{TM}}$, and Classmates $^{\mathrm{TM}}$. And the goal was to promote the freeexchange of ideas in and around our campus with limited restrictions placed on what individuals can or cannot do with their space.

During Phase II, we continue our AR/DR to formulate a stronger model for building CoPs. More specifically, we look to answer the following research questions:

1. Do individuals participate in and/or are they active members of existing knowledge communities?

2. Do individuals perceive value from stakeholderdefined OLCs?

3. What next steps should be considered in Phase III?

\subsection{Web 2.0 fosters CoPs}

Existing studies in online collaboration show that virtual communication patterns correspond in some fashion to real-life communication [28, 29]. As in F2F communication, members of an OLC should be able to state what they think, comment on what others have said, collaborate on common statements, and share information in many forms. Using popular OSN applications as models, we focused our efforts on the Web 2.0 technologies that they incorporate. Web 2.0 technologies, such as blogs, wikis, and peer-to-peer (P2P) file sharing, offer individuals with a suite of utilities that foster personal and group knowledge building. And increasingly, more individuals are gaining access and familiarizing themselves with these technologies, thus making their introduction into the classroom more-or-less seamless.

Research trends support these assumptions. Brescia and Miller [30] found that some benefits to using blogging in the classroom is to promote student reflection, engagement, portfolio building, and highlevel synthesizing activities. Rollett et al. [31] 
discovered that wikis were well suited for team activities providing individuals with the ability to easily exchange, integrate and develop information through asynchronous means.

\subsection{Elgg Online Learning Community}

During the planning stages of Phase I, we evaluated a variety of proprietary and open source software solutions comparing each based on cost, functionality, usability, extensibility and customizability. We chose the Elgg online learning environment for its range of features including blogging, file sharing, profile building, RSS, individual customization and peer networking.

Beyond these functional requirements, extensibility was a critical factor. The Elgg open source software provided us with the freedom to development new components and to customize the software to meet the needs of our school and project stakeholders. As one example, the requirement to support individual portfolio building and collaborative writing led to the addition of the wiki add-in. Figure 2 represents a screenshot of the Elgg homepage. As one mechanism to foster social presence, a user logs in and has access to recent activity across the site.

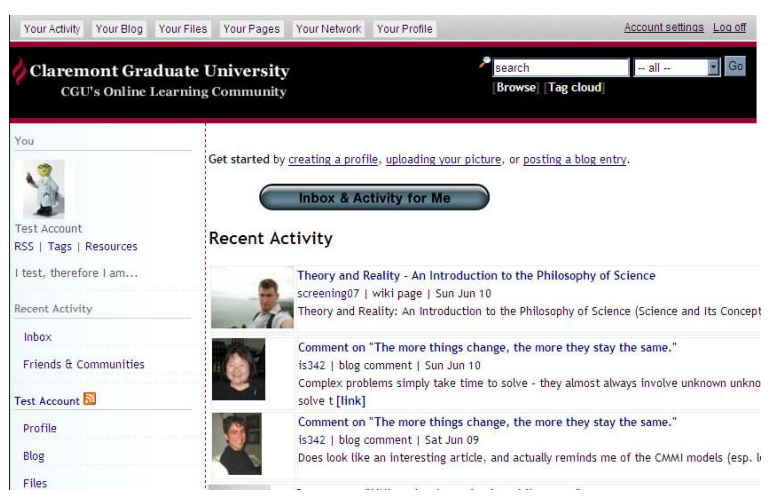

Figure 2. Elgg homepage

\subsection{Content Restrictions}

An important feature of Elgg, and supporting the idea of a stakeholder-controlled OLC, is the ability for individuals and communities to restrict access to information across a number of levels. Elgg accommodates this and also allows individuals to establish customized levels of access to restrict or grant access to a wider audience, including the Internet. Detailed in the next section, this feature was used extensively to keep content restricted at the community level and is similar to how traditional most CMS systems function. On the opposite end of the spectrum, by not setting restrictions, individuals or groups can use the tool to create publicly accessible content.

Figure 3 provides a screenshot of how individuals are able to set restrictions across a number of levels. The feature consists of a dropdown list that can be set for all site content including profile information, blogs, files and/or wiki pages.

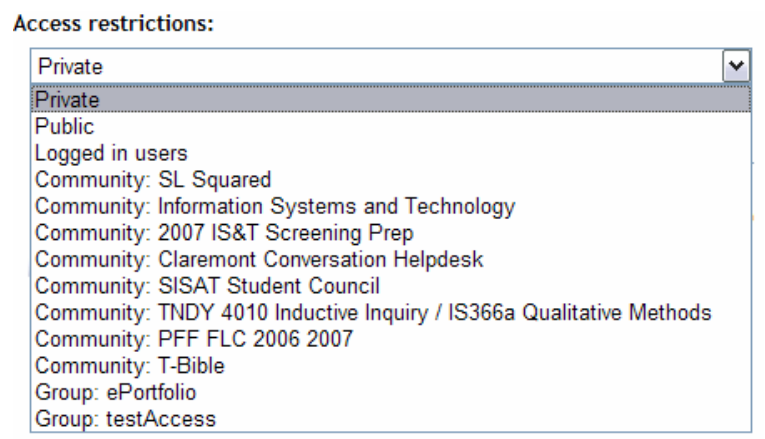

Figure 3. Content restrictions

\section{Implementation Site}

\subsection{Population}

In Phase II, as in Phase I, we focus on a specific population at our school, doctoral students taking transdisciplinary courses (t-courses). T-courses, offered exclusively to second-year doctoral students, provide students and faculty with the chance to work collaboratively and across multiple disciplines on a common set of questions and issues, while drawing from their own disciplinary training.

Focusing on the t-course population for Phase II provides us with the unique opportunity to measure the impact of the OLC on building community and knowledge across nascent communities, rather than focusing on individuals from established communities, such as those within specific disciplines.

T-courses also provide access to courses that, in the past, have relied primarily on traditional instructorfacilitated lecture and F2F discussion with little to no virtual collaboration. Where collaborative work was assigned, students would identify their own methods for collaborating, which, again, may or may not have consisted of a virtual component. Ultimately, there was no formal meeting place, virtual or real-life for students to meet and collaborate outside the classroom.

Although our research aims not to supplant the F2F interactions that have occurred in past t-courses, we hope to provide students and instructors with a blended learning approach, consisting of both F2F and virtual components. 


\subsection{Implementation}

Prior to the release of our software, we met regularly with project stakeholders and course instructors for the purposes of training and also to discuss how the OLC could augment course objectives. During these initial meetings, we focused on how instructors could align course syllabi with the software. For example, if a course required weekly assignments based on selective course readings, or guest lectures, we recommended the community blog as a viable option for individuals to express themselves. For more collaborative projects, we recommended that students use the wiki. In the end, it was left up to the instructor to decide how best to use the technologies, but we did help provide guidance and instruction on how they could best meet their specific course objectives.

Since implementing the OLC was not mandatory for each t-course, three of the five Spring 2007 instructors chose to implement the software.

\section{Results}

We relied on a variety of methods for collecting data including quantitative surveys and data log files. Although limited to varying degrees, each offered us one view of the impact our system had on building community and fostering knowledge sharing at our school.

\subsection{Pretest Results}

Prior to releasing the software across our population, we conducted a pretest. The pretest looked to capture general information about our population including user demographics and the willingness of individuals to share knowledge with and trust a CoP. The survey consisted of closed-ended questions and yielded 33 usable responses from our initial pool of 42 t-course participants ( $79 \%$ response rate).
Using a rudimentary 3-point scale, we assessed how familiar individuals were with the Web 2.0 technologies that comprised our tool. It is worthwhile to note that on average, our population was less familiar with many of the popular Web 2.0 technologies such as file sharing (1.6), wikis (1.6) and social networking (1.7). However, users were somewhat familiar with blogging (2.0), although it was likely that the majority did not maintain personal blogs themselves. Table 1 shows the distribution across Web 2.0 technologies.

Table 1. Technology assessment

\begin{tabular}{|l|l|}
\hline \multicolumn{2}{|c|}{ 1=not familiar, $2=$ somewhat familiar, $3=$ very familiar } \\
\hline Technology & \multicolumn{1}{c|}{ Average Score } \\
\hline Social Networking & 1.7 \\
\hline Blog & 2 \\
\hline Wiki & 1.6 \\
\hline File Sharing & 1.6 \\
\hline
\end{tabular}

For aspects of KS and trust, we relied on a preexisting instrument developed by Usoro et al. [32]. From the start, it was alarming that $59 \%$ of respondents disagreed or strongly disagreed with the statement, "I frequently share knowledge with the community." This reflected closely with the response that $61 \%$ disagreed or strongly disagreed that they make an effort to share knowledge. Further supporting the lack of KS among our population was the low levels of agreement that individuals considered their contributions useful for the community (9\%), or that they were of any great value (14\%) with $30 \%$ and $27 \%$ of the population disagreeing or strongly disagreeing with these statements.

On a positive note, $42 \%$ felt that they were knowledgeable contributors to the community, possibly indicating that what they do disseminate to the community is in fact pertinent and thoughtful contributions. Table 2 represents the distribution of responses across items related to $\mathrm{KS}$ in a $\mathrm{CoP}$.

Table 2. KS in CoPs

\begin{tabular}{|c|c|c|c|c|c|c|}
\hline Survey Item & 1 & 2 & 3 & 4 & 5 & $\mathbf{N A}$ \\
\hline I frequently share knowledge with the community. & $6 \%$ & $14 \%$ & $18 \%$ & $41 \%$ & $18 \%$ & $3 \%$ \\
\hline I am an active contributor within the community. & $11 \%$ & $21 \%$ & $38 \%$ & $18 \%$ & $9 \%$ & $3 \%$ \\
\hline I make an effort to engage in knowledge building. & $6 \%$ & $18 \%$ & $35 \%$ & $30 \%$ & $9 \%$ & $3 \%$ \\
\hline I make an effort to share knowledge with the community. & $6 \%$ & $6 \%$ & $21 \%$ & $50 \%$ & $11 \%$ & $6 \%$ \\
\hline My contributions are found useful. & $6 \%$ & $3 \%$ & $56 \%$ & $21 \%$ & $9 \%$ & $6 \%$ \\
\hline My contributions enable others to develop new knowledge. & $6 \%$ & $3 \%$ & $62 \%$ & $18 \%$ & $6 \%$ & $6 \%$ \\
\hline I am a knowledgeable contributor to the virtual community. & $18 \%$ & $24 \%$ & $32 \%$ & $18 \%$ & $3 \%$ & $6 \%$ \\
\hline The knowledge I share with the community has a positive impact. & $6 \%$ & $6 \%$ & $68 \%$ & $6 \%$ & $6 \%$ & $9 \%$ \\
\hline My quality and timely contributions are of great value to others. & $6 \%$ & $9 \%$ & $53 \%$ & $21 \%$ & $6 \%$ & $6 \%$ \\
\hline
\end{tabular}


Closely mirroring our results for KS, individuals also perceived low-levels of trust in KS communities (represented in detail in Table 3). Although roughly $50 \%$ of respondents remained neutral across many of the survey items, over $30 \%$ indicated a lack of trust in various aspects of the knowledge community. More specifically, $56 \%$ of respondents disagreed or strongly disagreed with the statement that the community would do its best to help them and $44 \%$ disagreed or strongly disagreed that the community was a valid source of expertise and knowledge. Furthermore, 38\% of individuals disagreed or strongly disagreed that the community shares knowledge well.

Table 3. Trust in CoPs

\begin{tabular}{|c|c|c|c|c|c|c|}
\hline Survey Item & 1 & 2 & 3 & 4 & 5 & NA \\
\hline I believe that the virtual community would act in my best interest & $3 \%$ & $0 \%$ & $62 \%$ & $24 \%$ & $6 \%$ & $6 \%$ \\
\hline If I required help, the community would do its best to help me & $0 \%$ & $0 \%$ & $38 \%$ & $50 \%$ & $6 \%$ & $6 \%$ \\
\hline The community is interested in my well-being & $0 \%$ & $0 \%$ & $53 \%$ & $35 \%$ & $6 \%$ & $6 \%$ \\
\hline The community is truthful in its dealings with me & $0 \%$ & $3 \%$ & $50 \%$ & $35 \%$ & $6 \%$ & $6 \%$ \\
\hline I would characterise the community as honest & $0 \%$ & $0 \%$ & $50 \%$ & $38 \%$ & $6 \%$ & $6 \%$ \\
\hline The community would keep its commitments & $0 \%$ & $3 \%$ & $56 \%$ & $29 \%$ & $6 \%$ & $6 \%$ \\
\hline The community is genuine and sincere & $0 \%$ & $3 \%$ & $53 \%$ & $32 \%$ & $6 \%$ & $6 \%$ \\
\hline The community is a competent and effective source of expertise & $0 \%$ & $0 \%$ & $53 \%$ & $32 \%$ & $9 \%$ & $6 \%$ \\
\hline The community performs its role of sharing knowledge very well & $0 \%$ & $3 \%$ & $53 \%$ & $35 \%$ & $3 \%$ & $6 \%$ \\
\hline Overall, the community is a source of expertise and knowledge & $0 \%$ & $3 \%$ & $47 \%$ & $38 \%$ & $6 \%$ & $6 \%$ \\
\hline In general, the community is very knowledgeable & $0 \%$ & $0 \%$ & $56 \%$ & $32 \%$ & $6 \%$ & $6 \%$ \\
\hline I trust the community not to forward or share my sensitive material & $0 \%$ & $12 \%$ & $47 \%$ & $26 \%$ & $6 \%$ & $9 \%$ \\
\hline
\end{tabular}

\subsection{Site Usage}

The pretest provided us with interesting information prior to assessing the impact of the OLC. After one semester we looked at the degree to which the t-courses used the OLC. Although each utilized the tool in different capacities, each course utilized the OLC extensively. Table 4 provides a breakdown for each technology.

\section{Table 4. Restrictions across content}

\begin{tabular}{|l|l|l|l|}
\hline Feature & \multicolumn{1}{|c|}{ Items Created } & \multicolumn{1}{c|}{ Rest. } & \multicolumn{1}{c|}{$\%$} \\
\hline Blogs & 227 & 181 & $79 \%$ \\
\hline Wikis & $\begin{array}{l}84 \text { unique wiki pages } \\
696 \text { total pages }\end{array}$ & 10 & $8 \%$ \\
\hline Files & 114 & 102 & $90 \%$ \\
\hline
\end{tabular}

Specifically, blogs accounted for the majority of content resulting in 227 new blog entries across three courses. Not surprisingly, the majority of blog creations were kept restricted to the community in order to respect individuals' academic privacy. Only $10 \%$ were kept unrestricted and could have been due to a lapse on the blogger's part. Keeping content restricted was often mandated by the course instructor.

Similarly, $90 \%$ of file additions were kept restricted, possibly, for copyright purposes.

A total of 696 wiki pages were edited with 84 unique pages created. Surprisingly, only $8 \%$ of the wiki pages were kept restricted. In one class wiki pages were publicly editable, meaning anyone on the Internet can edit that page. In another, wiki content was set to moderated so that external viewers are only able to view the content and not edit it.

\subsection{Posttest Results}

With successful amounts of traffic and a fair amount of usage, we looked to measure what value users perceived from the OLC. Through a posttest, we measured how effective the tool was in building community, fostering collaboration and supporting knowledge creation. Closed-ended questions were distributed to the same population of $t$-course participants (42 individuals) and resulted in 30 usable responses (or a $71 \%$ response rate).

Despite low levels of perceived KS and trust in CoPs among our population, results from our posttest reflected positively on our OLC.

As part of a 5-point scale, we measured the overall impact of the OLC including ease of use. Providing support for our results in Phase I, we discovered that only $10 \%$ disagreed with the notion of an OLC at our school, while $27 \%$ remained neutral and $64 \%$ either agreed or strongly agreed. $70 \%$ percent found the website easy to use and 50\% responded that the OLC helped in reflecting on class progress. Table 5 provides a complete distribution of responses. 
Table 5. Overall user experience

\begin{tabular}{|c|c|c|c|c|c|}
\hline Survey Item & 1 & 2 & 3 & 4 & 5 \\
\hline Our school should have an OLC. & $17 \%$ & $47 \%$ & $27 \%$ & $7 \%$ & $3 \%$ \\
\hline OLC was easy to use & $13 \%$ & $57 \%$ & $23 \%$ & $7 \%$ & $0 \%$ \\
\hline OLC helped me reflect on my class progress & $10 \%$ & $40 \%$ & $33 \%$ & $17 \%$ & $0 \%$ \\
\hline I plan to keep in contact with other students through the website & $7 \%$ & $13 \%$ & $33 \%$ & $47 \%$ & $0 \%$ \\
\hline
\end{tabular}

Unfortunately, $47 \%$ stated that they do not plan to continue contact with peers through the OLC. This, however, could simply be a reflection of the nature of the t-course, with individuals collaborating for the purposes of one class, disparate from their respective discipline. During subsequent phases we plan to implement the OLC across our institution, and through this we believe we can reach the necessary critical mass for its continued success.

Adapting Gunawardena and Zittle's [33] original questionnaire measuring social presence, we discovered that the majority of users were amenable to the idea of an OLC. $76 \%$ of individuals agreed that the
OLC helped them feel like part of the community and $76 \%$ agreed that a strong sense of community existed. This would help explain why the overwhelming majority of individuals were comfortable conversing (90\%) and participating in course discussions $(97 \%)$ through the shared medium. Furthermore, 93\% of users responded that they felt comfortable interacting with others through the OLC and $83 \%$ of felt that their point of view was acknowledged. Overall, $87 \%$ felt the OLC was an excellent medium for social interaction and an equal number of respondents felt that the community also helped to improve learning. Table 6 offers a complete distribution of responses on social presence.

Table 6. Building social capital

\begin{tabular}{|l|l|l|l|l|l|l|}
\hline 1=Strongly Agree, 2=Agree, 3=Agree Somewhat, 4=Disagree Somewhat, 5= Disagree, 6=Strongly Disagree \\
\hline \multicolumn{1}{|c|}{ Survey Item } & $\mathbf{1}$ & $\mathbf{2}$ & $\mathbf{3}$ & $\mathbf{4}$ & $\mathbf{5}$ & $\mathbf{6}$ \\
\hline The tool was an excellent medium for social interaction & $13 \%$ & $27 \%$ & $47 \%$ & $10 \%$ & $3 \%$ & $0 \%$ \\
\hline I felt comfortable conversing through this medium & $20 \%$ & $33 \%$ & $37 \%$ & $7 \%$ & $3 \%$ & $0 \%$ \\
\hline I felt comfortable introducing myself in this course & $23 \%$ & $37 \%$ & $37 \%$ & $0 \%$ & $3 \%$ & $0 \%$ \\
\hline The tool helped me feel like part of the community & $3 \%$ & $30 \%$ & $43 \%$ & $13 \%$ & $10 \%$ & $0 \%$ \\
\hline I felt comfortable participating in course discussions & $23 \%$ & $57 \%$ & $17 \%$ & $3 \%$ & $0 \%$ & $0 \%$ \\
\hline I felt comfortable interacting with others & $23 \%$ & $47 \%$ & $23 \%$ & $7 \%$ & $0 \%$ & $0 \%$ \\
\hline My point of view was acknowledged by others & $23 \%$ & $33 \%$ & $27 \%$ & $7 \%$ & $7 \%$ & $3 \%$ \\
\hline Able to form different impressions of others & $17 \%$ & $37 \%$ & $37 \%$ & $7 \%$ & $3 \%$ & $0 \%$ \\
\hline I learned a lot during this course & $27 \%$ & $30 \%$ & $30 \%$ & $13 \%$ & $0 \%$ & $0 \%$ \\
\hline There was a strong sense of community in this course & $13 \%$ & $40 \%$ & $23 \%$ & $17 \%$ & $7 \%$ & $0 \%$ \\
\hline The course community improved my learning & $10 \%$ & $50 \%$ & $27 \%$ & $7 \%$ & $7 \%$ & $0 \%$ \\
\hline
\end{tabular}

In a stakeholder-defined OLC, ownership of content should be placed in the hands of the individual creating the content. $66 \%$ of respondents agreed or strongly agreed that a sense of ownership over their content existed while $63 \%$ viewed this as important concept. Similarly, $66 \%$ of respondents agreed or strongly agreed that restricting access was important. Table 7 details the complete distribution of responses.

Table 7. Sense of ownership

\begin{tabular}{|l|c|c|c|c|c|c|}
\hline 1=Strongly Agree, $2=$ Agree, 3=Neutral, 4=Disagree, 5=Strongly Disagree, NA=No Answer \\
\hline \multicolumn{1}{|c|}{ Survey Item } & $\mathbf{1}$ & $\mathbf{2}$ & $\mathbf{3}$ & $\mathbf{4}$ & $\mathbf{5}$ & NA \\
\hline I felt a sense of ownership over my posted content & $13 \%$ & $53 \%$ & $27 \%$ & $7 \%$ & $0 \%$ & $0 \%$ \\
\hline Ownership over my content was important & $30 \%$ & $33 \%$ & $33 \%$ & $0 \%$ & $0 \%$ & $3 \%$ \\
\hline Ability to personalize/customize my profile was important & $17 \%$ & $30 \%$ & $37 \%$ & $17 \%$ & $0 \%$ & $0 \%$ \\
\hline Ability to restrict content was important to me & $30 \%$ & $33 \%$ & $17 \%$ & $17 \%$ & $3 \%$ & $0 \%$ \\
\hline
\end{tabular}

We also looked to measure how effective the openness of the OLC was in KS motivation. Results show that $50 \%$ of individuals felt that seeing their peer's work helped with their own work. The majority 
of individuals $(70 \%)$ did respond that making their work accessible increased their motivation to do quality work. Table 8 details the distribution of responses across $\mathrm{KS}$ as motivating factors in an OLC.

Table 8. KS as motivation

\begin{tabular}{|c|c|c|c|c|c|}
\hline Survey Item & 1 & 2 & 3 & 4 & 5 \\
\hline Seeing my classmate's work helped my own writing. & $3 \%$ & $47 \%$ & $30 \%$ & $20 \%$ & $0 \%$ \\
\hline Having work accessible to classmates increased my motivation to do a good job. & $20 \%$ & $50 \%$ & $20 \%$ & $7 \%$ & $3 \%$ \\
\hline Having work accessible outside my class increased my motivation to do a good job. & $10 \%$ & $33 \%$ & $37 \%$ & $17 \%$ & $3 \%$ \\
\hline
\end{tabular}

\section{Discussion and Implications}

Prior to implementing our software there was no persistent space for community building and $\mathrm{KS}$ outside of the classroom. In this research we look to correct this problem by implementing a stakeholderdefined OLC. For several reasons we believe courses implementing the OLC design achieved significant advantages over those t-courses opting out of the pilot project (and ultimately choosing not to implement a virtual agent).

T-courses are inherently collaborative and often require individuals to communicate with one another outside the classroom. Therefore providing students with access to a virtual space from the onset helps to streamline and help manage such asynchronous collaboration. For courses choosing not to implement the OLC, no preexisting virtual space existed, forcing students to discover their own means and methods for communicating.

Furthermore, the persistent nature of the OLC provides students with access to a breadth of knowledge available during and after the course. Although only $20 \%$ indicated interest to continue interacting through the software (Table 5), nothing prevents an individual from returning to formulate their own knowledge communities and/or recruit new members later on. The bottom-up (student-owned) nature of the software provides all members with complete capabilities to establish new communities and also explore the over 60 communities existing across the OLC. This option, of course, is not available for students not participating in the OLC pilot.

Finally, the OLC provided students with the experience of using Web 2.0 technologies in a blendedlearning environment. As identified in the background, Web 2.0 technologies are fast-becoming fused into various aspects of higher education and exposing a predominantly doctoral population early on in their research career helps prepare those students for teaching and research careers that may use similar tools in the future. This was particularly important, considering that our population was found to be less familiar with such popular technologies as wiki writing, file sharing and social networking (Table 1).

We also feel that our research provides generalizations outside our respective institution. In higher education, instructor controlled learning environments are often the norm (i.e. traditional CMS tools). Our decision to use and extend the Elgg open source software offers a unique model that emphasizes students' autonomy within the larger community. This construct was rated highly in our posttest with over $60 \%$ of respondents indicating ownership and control as important features (Table 7).

Additionally, data collected from the pretest indicated a general opposition towards knowledge communities (Tables $2 \& 3$ ). By providing individuals with control over their content in addition to providing content aggregation tools, we feel we have helped mitigate many of the negative perceptions towards knowledge communities. As a result, posttest data showed a positive response to the OLC with $76 \%$ perceiving a strong sense of community and $60 \%$ perceiving that the community also facilitated in learning (Table 6). Being a member of the community also provided motivation for students and 70\% responded that having work accessible to classmates increased their motivation to contribute quality work.

Finally, we feel we offer a valid contribution to the emerging hybrid AR/DR model. By modifying and extending the Elgg open source software we were able to meet the needs of a specific population at our school. With a proof-of-concept established, we look to refine and measure the effects of the extended Elgg software design as we expand the scope of our research to meet the needs of our greater institution.

\section{Limitations and Next Steps}

During Phase II of our AR/DR cycle we focused on the narrow sample size of three t-courses, resulting in small base population of 42 students. Although the tcourse provides a unique opportunity to assess community development across diverse disciplines, they offer limited insight on community building from 
within a discipline. Of the sparse qualitative feedback we received, individuals indicated a lack of interest in continuing to use the OLC because they perceived no value in doing so outside their respective disciplines. For future phases, we plan to release the OLC campuswide, providing individuals with the opportunity for intradisciplinary KS as well.

Furthermore, heretical to the notion of a CoP, individuals were required to use the OLC as a part of the course participation, instead of participation being purely voluntary. In subsequent phases, students will be added automatically into the OLC but participation will not be mandatory.

Additionally, our research currently lacks any formal baseline. As primarily an AR project, we focused, first, on providing a system to extend scholarly conversation and interaction to the virtual realm. An immediate next step will look to measure the outcomes of our OLC against data collected measuring the effects of our school's CMS software.

Finally, although the initial acceptance of our tool is a critical issue in determining whether it is successful, its continued use is at least as important [34]. We hope that as our software stabilizes, its continued usage will foster more creative and advanced research opportunities, including the development of niche communities of interest (CoI) and bring different CoPs together to provide greater opportunity for social creativity [35].

\section{Conclusion}

Over the past year, our project team has added a virtual component to the scholarly conversation at our school. Over 250 graduate students and faculty currently participate with new members joining daily. Our software has achieved a measure of success in providing an asynchronous online component for students and faculty to collaborate and share knowledge in courses and on external projects.

Guided by theories of online community building, direct and indirect data from Phase II of our AR/DR project indicates that although users may be reluctant to participate knowledge sharing communities, when provided with a stakeholder-defined OLC, users perceive high levels of value in an online CoP.

Although a number of limitations exist, we believe that our research provides a proof-of-concept and offers interesting insight into the application of stakeholder-defined OLCs within an academic setting. Should our results continue across future implementations, stakeholder-defined OLCs may provide a unique solution for increased scholarship at our school as well as a valid alternative to, or integration with, more traditional CMS solutions.

\section{References}

[1] Lave, J. and Wenger, E., Situated Learning: Legitimate Peripheral Participation, Cambridge University Press, 1991.

[2] E.C. Adams and C. Freeman, "Communities of practice: bridging technology and knowledge assessment", Journal of Knowledge Management, vol. 4 pp. 3844, 2000.

[3] Wenger E., Communities of Practice, Learning, Meaning, and Identity, Cambridge, MA: Cambridge University Press, 1998.

[4] B. Daniel, R.A. Schwier and G. McCalla, "Social Capital in Virtual Learning Communities and Distributed Communities of Practice", Canadian Journal of Learning and Technology, vol. 29, 2003.

[5] J. Nahapiet and S. Ghoshal, "Social capital, intellectual capital, and the organizational advantage", Academy of Management Review vol. 23, pp. 242266, 1998.

[6] E. Lesser and L. Prusak, "Communities of practice, social capital and organizational knowledge", Knowledge and Communities pp. 123-131, 2000.

[7] Huysman and Wulf, "Information Technology in Building and Sustaining the Relational Base of Communities", The Information Society, vol. 21, pp. $81-89,2005$.

[8] J. Mason and P. Lefrere, "Trust, collaboration, e-learning and organisational transformation", International Journal of Training and Development, vol. $7 \mathrm{pp}$. 259-270, 2003.

[9] K. Bielaczyc, and A. Collins, "Learning communities in classrooms: A reconceptualization of educational practices", in C. M. Reigeluth (Ed.) Instructionaldesign theories and models: A new paradigm of instructional theory, New Jersey: Lawrence Erlbaum, 269-292, 1999.

[10] C.M. Johnson, "A survey of current research on online communities of practice", Internet and Higher Education, vol. 4 pp. 45-60, 2001.

[11] S.L. Pan and D.E. Leidner, "Bridging Communities of Practice with Information Technology in Pursuit of Global Knowledge Sharing", Journal of Strategic Information Systems Issue 12 pp. 71-88, 2003.

[12] P. Hendriks, "Why share knowledge? The influence of ICT on the motivation for knowledge sharing", Knowledge and Process Management, vol. 6, pp. 91-100, 1999.

[13] M. Sharratt and A. Usoro, "Understanding KnowledgeSharing in Online Communities of Practice", Electronic Journal of Knowledge Management, vol. 1, 2003.

[14] Davenport, T.H. and Prusak, L., Working Knowledge: How Organizations Manage What They Know, Boston: Harvard Business School Press, 1998.

[15] J. Preece, "Sociability and usability in online communities: determining and measuring success", Behavior and Information Technology, vol. 20, pp. 347-356, 2001.

[16] K. Wathne, J. Roos and G. von Krogh "Towards a theory of knowledge transfer in a cooperative 
context", in G. von Krogh \& J. Roos (eds.) London: Sage Publications, 1996.

[17] A. Edmondson, "Psychological safety and learning behavior in work teams", Administrative Science Quarterly, vol. 44, pp. 350-383, 1999.

[18] Palloff, R. and Pratt, K., Building learning communities in cyberspace: effective strategies for the online classroom, San Francisco: Jossey-Bass, 1999.

[19] J.R. Savery and T.M. Duffy, "Problem Based Learning: An instructional model and its constructivist framework", in B. Wilson (ed.). Constructivist Learning Environments: Case Studies in Instructional Design, Educational Technology Publications, Englewood Cliffs, NJ, 1996.

[20] Hagstrom, F. and Wertsch, J. V. The Social Construction of identity: The Clinical Challenge. Topics in Language Disorders. Vol. 3, pp. 162-173, 2004.

[21] D. Squires, "Educational software and learning: Subversive use and volatile design." Hawaiian International Conference on System Sciences, 1999.

[22] Matthews, M.R, "Constructivism and Science Education: A Further Appraisal", Journal of Science Education and Technology, vol. 11, 2002.

[23] C.H. Tu, "The measurement of social presence in an online learning environment", International Journal of eLearning, Corporate, Government, Healthcare, \& Higher Education, AACE, Vol. 2 pp. $34-45,2002$.

[24] E. Stacey, "Social Presence Online: Networking Learners at a Distance", Education and Information Technologies, Kluwer Academic Publishers, vol. 7, pp. 287-294, 2002.

[25] S. Bødker, "A human activity approach to user interfaces", Human-Computer Interaction, vol. 4, pp. 171- 195, 1989.

[26] K. Issroff and E. Scanlon, "Case studies revisited- what can Activity Theory offer?", Proceedings of First Euro-CSCL Conference, Maastricht, 2001.
[27] R. Heckman and H. Annabi, "Cultivating Voluntary Online Learning Communities in Blended Environments", Journal of Asynchronous Learning Networks, vol. 10, 2006.

[28] S. Redfern and N. Naughton, "Collaborative Virtual Environments to Support Communication and Community in Internet-Based Distance Education", Journal of Information Technology Education, vol. $1,2002$.

[29] M. Rohde, L. Reinecke, B. Pape, M. Janneck, "Community-Building with Web-Based Systems Investigating a Hybrid Community of Students", Computer Supported Cooperative Work (CSCW), vol. 13, 2004.

[30] W. Brescia and M. Miller, "What's it Worth? The Perceived Benefits of Instructional Blogging." Electronic Journal for the Integration of Technology in Education, 2006.

[31] H, Rollett, M. Lux, M. Strohmaier, G. Dosinger, K. Tochtermann, "The Web 2.0 way of learning with technologies", International Journal of Learning Technology, vol. 3, pp. 87-107, 2007.

[32] A. Usoro, M. Sharratt, E. Tsui, "An Investigation into Trust as an Antecedent to Knowledge Sharing in Virtual Communities of Practice", Computing and Information Systems Journal, University of Paisley, vol. 10, 2006.

[33] C.N. Gunawardena, and F.J. Zittle, "Social presence as a predictor of satisfaction within a computermediated conferencing environment". The American Journal of Distance Education, vol. 11, pp. 8-26, 1997.

[34] A. Bhattacherjee, "Understanding information systems continuance: An expectation-confirmation model", MIS Quarterly, vol. 25, pp. 351-370, 2001.

[35] G. Fischer, "Communities of interest: Learning through the interaction of multiple knowledge systems", In Proceedings of the 24th Annual Information Systems Research Seminar in Scandinavia, Ulvik, Norway, pp. 1-14, 2001. 